\title{
Dental Hygiene, Dental, and Medical Students' OMFS/Hospital Dentistry-Related Knowledge/Skills, Attitudes, and Behavior: An Exploration
}

\author{
Stephanie M. Munz, DDS; Roderick Y. Kim, DDS, MD; Tyler J. Holley, DDS; \\ John N. Donkersloot, MD; Marita R. Inglehart, Dr phil habil
}

Abstract: Engaging other health care providers in oral health-related activities and interprofessional care (IPC) could increase access to oral health care for underserved populations in the U.S. The aims of this study were to assess dental hygiene, dental, and medical students' intra- and interprofessional and oral and maxillofacial surgery (OMFS)/hospital dentistry-related knowledge/skills, attitudes, and behavior; determine whether first and second year vs. third and fourth year cohorts' responses differed; and explore how intra- and interprofessional knowledge was related to interprofessional education (IPE) and interprofessional attitudes and behavior. Data were collected between April 2014 and May 2015 from 69 dental hygiene, 316 dental, and 187 medical students. Response rates across classes for the dental hygiene students ranged from $85 \%$ to $100 \%$; $24 \%$ to $100 \%$ for the dental students; and $13 \%$ to $35 \%$ for the medical students. The results showed that the medical students had lower oral healthrelated and interprofessional knowledge and less positive attitudes about oral health-related behavior, IPE, and interprofessional teamwork than the dental hygiene and dental students. While third- and fourth-year medical students' interprofessional knowledge/skills and behavior were higher than those of first- and second-year students, the two groups' IPE-related and interprofessional attitudes did not differ. The students' knowledge correlated with their IPE and interprofessional communication-related skills and behavior, but not with their interprofessional attitudes. These dental hygiene, dental, and medical students' OMFS/ hospital dentistry-related knowledge/skills and behavior increased over the course of their academic programs, while their IPErelated and intra- and interprofessional attitudes, especially for medical students, did not improve over time. OMFS and hospital dentistry units in medical centers offer distinctive opportunities for IPE and IPC. Utilizing these units may be one way to ensure that graduating providers are motivated to engage in IPC in their practice, thus contributing to reducing oral health disparities and increasing access to oral care for underserved populations.

Dr. Munz is Director of the General Practice Residency Program and Clinical Assistant Professor, Department of Oral and Maxillofacial Surgery/Hospital Dentistry, University of Michigan School of Dentistry; Dr. Kim is a sixth-year resident, Oral and Maxillofacial Surgery Program, University of Michigan School of Dentistry and Medical School; Dr. Holley is a third-year resident, Oral and Maxillofacial Surgery Program, University of Nebraska School of Medicine; Dr. Donkersloot is a second-year resident, General Surgery Program, St. Joseph Hospital, Ypsilanti, MI; and Dr. Inglehart is Professor, Department of Periodontics and Oral Medicine, School of Dentistry and Adjunct Professor, Department of Psychology, College of Literature, Science, and Arts, University of Michigan. Direct correspondence to Dr. Marita R. Inglehart, Department of Periodontics and Oral Medicine, University of Michigan School of Dentistry, 1011 N. University Street, Ann Arbor, MI 48109-1078; 734-763-8073; mri@umich.edu.

Keywords: dental education, dental hygiene education, medical education, interprofessional education, interdisciplinary health team, oral and maxillofacial surgery

Submitted for publication 11/9/15; accepted 6/15/16

$\mathrm{T}$ The first U.S. surgeon general's report on oral health clearly showed that certain segments of the U.S. population such as patients from lower socioeconomic and/or underrepresented minority groups and patients with special health care needs have disproportionate amounts of dental disease and face severe challenges when seeking oral health care services. ${ }^{1}$ While oral health professionals play a central role in providing dental care for these patients, support from other health care providers could be quite beneficial. Other health care providers, for instance, may have access to patient populations not seen by dental care providers on a regular basis, such as very young pediatric patients who come for wellvisit appointments to pediatricians but may not see a dentist until they are older. ${ }^{2}$ Non-dental providers can therefore play an important role in reducing oral health disparities if they engage in interprofessional care (IPC) with dental care providers. ${ }^{3}$ For example, they can provide oral health education for patients and their parents/caregivers, deliver preventive oral health care services such as fluoride varnish applications and sealants, and refer patients to dentists when needed. ${ }^{4-6}$ At the same time, dental professionals 
should be able to conduct a number of primary medical care activities, such as screening for diabetes ${ }^{7}$ and hypertension and assessing risk for conditions such as obstructive sleep apnea. ${ }^{7-9}$

In addition, a substantial number of patients have quite complex multifactorial dental, medical, and behavioral conditions and needs such as frail elderly persons and individuals with craniofacial anomalies, cancer, diabetes, or chronic illnesses. ${ }^{10-15}$ These patients' oral and systemic health may be significantly associated, and their oral health may suffer as a function of the medications they take or the treatments they receive. They will therefore receive optimal care only if they are treated by an interprofessional team of health care providers because IPC and coordinated treatment planning are essential for providing the comprehensive care these patients require. IPC has the potential to improve health, enhance patients' health care experiences, and reduce health care costs. ${ }^{16}$

Educating all health professions students about oral health issues and the importance of IPC is therefore important. ${ }^{3,17-19}$ Accordingly, accreditation standards for dental hygiene programs ${ }^{20}$ require implicitly and standards for dental ${ }^{21}$ and medical schools ${ }^{22}$ require explicitly that graduating students be competent to engage in IPC. Intraprofessional programs have been developed to increase collaborations between dental and dental hygiene students, ${ }^{23-26}$ and interprofessional education (IPE) programs have been developed for dental and medical students ${ }^{19,27,28}$ and dental hygiene and medical students. All these efforts are evidence of the fact that IPE is an emerging pedagogy. ${ }^{29,30} \mathrm{IPE}$ has even been initiated at the undergraduate level. ${ }^{31,32}$ The aim of IPE is to teach the skills future health care providers need to successfully collaborate with their counterparts from other professions and to engage in IPC with respect for other professionals' expertise and skills., ${ }^{4,11,33}$

Dental hygiene, dental, and medical care providers have interactions with oral and maxillofacial surgeons and hospital dentists, whose expertise and training are based in both dentistry and medicine. It is therefore interesting to explore what dental hygiene, dental, and medical students know about these disciplines; what attitudes they have about intraprofessional education and practice (within the oral health profession), IPE, IPC, and collaborations with oral and maxillofacial surgery (OMFS) and hospital dentistry; and in which intraprofessional and IPC-related behaviors they engage. Research has found that while medical students' and physicians' knowledge about providing oral health care services was lacking, ${ }^{34,35}$ their attitudes were generally positive. ${ }^{27,36,37}$ Even more important than attitudes is actual IPC-related behavior. Educational programs that encourage collaborative practice between medical and dental students $^{38,39}$ as well as between dental and dental hygiene students ${ }^{40}$ have found that behaviors shifted toward productive collaboration in those contexts.

It is important to understand how dental hygiene, dental, and medical students' intraprofessional and IPC-related knowledge/skills, attitudes, and behaviors differ and whether third- and fourth-year students differ from first- and second-year students by showing improved knowledge/skills, better attitudinal responses, and increased intraprofessional and IPC-related behavior. Increasing levels of education and, as a consequence, increased knowledge and improved skills may not only result in better IPC, but also in more appropriate referrals, recognition of others' roles and responsibilities, increased commitment to communication, and the building of a sense of participation in a team. ${ }^{38,41,42}$ These concepts are represented repeatedly as the core competencies of IPE moving toward IPC. ${ }^{43}$ Gaining a better understanding of how IPC-related knowledge/skills, attitudes, and behavior are related would therefore be quite beneficial. Based on these considerations, the aims of our study were to assess dental hygiene, dental, and medical students' intra- and interprofessional and OMFS/hospital dentistry-related knowledge/ skills, attitudes, and behavior; determine whether first- and second-year vs. third- and fourth-year cohorts' responses differed; and explore how intraand interprofessional knowledge was related to the students' IPE-related and interprofessional attitudes and behavior.

\section{Methods}

This study was determined to be exempt from oversight by the Institutional Review Board for the Behavioral and Health Sciences at the University of Michigan (HUM\#00077177). A convenience sample of dental hygiene, dental, and medical students at the University of Michigan was used for the study, conducted between April 2014 and May 2015. Dental hygiene is a three-year program at the University of Michigan School of Dentistry; however, dental hygiene students are admitted to the program after they have acquired certain prerequisites during a first year of undergraduate education at another college 
or university. Therefore, the dental hygiene students were in their second, third, and fourth years, while both the dental and medical students were in their first, second, third, and fourth years.

Given that the differences between the average scores of dental hygiene, dental, and medical students were of interest, an a priori power analysis was conducted with the G3.1.3. Power Analysis Program (www.psycho.uni-duesseldorf.de/abteilungen/ aap/gpower3/) to compute the sample size needed when conducting a univariate analysis of variance to test whether the three groups' mean scores differed significantly. Assuming an alpha error probability of 0.05 , a medium effect size of 0.25 on the five-point scale, and a power of 0.95 , the results showed that a total sample size of 252 respondents was required.

The survey was based on a previous validated and reliable instrument developed by the study team in a project concerning IPE with nursing and dental students. ${ }^{44}$ We used this adapted survey because no previous instrument focused explicitly on knowledge/skills, attitudes, and behavior related to IPC in OMFS and hospital dentistry units. The survey was pretested with ten dental students. Based on those pilot test results, minor changes in question wording and survey layout were made. The students either received a paper-and-pencil survey at the end of regularly scheduled classes or were recruited with an email that explained the study's purpose and asked them to volunteer to take to a Web-based survey by using a link provided in the email.

The survey consisted of four parts. Part 1 was a general introduction section with demographic and educational questions, such as in which program and in which program year the students were enrolled. Part 2 consisted of three sets of oral health-related knowledge questions: 1) five yes/no questions about the respondents' oral and maxillofacial knowledge; 2) six five-point rating scale questions exploring how much the respondents knew about OMFS and hospital dentistry-related issues; and 3) 11 yes/no questions asking if respondents could diagnose 11 oral health-related conditions. Part 3 focused on assessing respondents' attitudes toward oral and maxillofacialrelated IPE (five questions); IPC-related knowledge (six questions); ability to recognize/manage various health conditions (nine questions); attitudes toward intra- and interprofessional collaborations (five questions); and attitudes toward consults/referrals to OMFS and hospital dentistry units (18 questions). Part 4 contained 14 oral health-related behavior questions.
The paper-and-pencil responses were entered into an SPSS Version 22 (IBM Corp., Armonk, NY, USA) data file, and the Web-based responses were downloaded from the website as an Excel file and imported into SPSS. Descriptive statistics such as frequency distributions, percentages, and means were computed to provide an overview of the responses. Factor analyses (extraction method: Principal Component Analysis; rotation method: Varimax Rotation) were used to determine the factor structure of the attitudinal items. Cronbach's alpha inter-item consistency coefficients were computed to determine the reliability of the constructed subscales. Inferential statistics (univariate analyses of variance) were used to determine whether the three groups of respondents (dental hygiene, dental, and medical students) and students in the first and second vs. third and fourth years of each program differed significantly in their mean responses. Pearson correlation coefficients were computed to determine relationships between the three knowledge indices and the attitudinal and behavior indices. A $p<0.05$ was used as the level of significance for the group comparisons. Given that a large number of correlations were computed, a Bonferroni correction was used, and $p<0.01$ was used to determine the significance of the correlation coefficients.

\section{Results}

Data were collected from 69 dental hygiene, 316 dental, and 187 medical students. Among the dental hygiene students, $100 \%$ of the second-year (DH2), $100 \%$ of the third-year (DH3), and $85 \%$ of the fourth-year (DH4) students responded to the survey. A similar pattern of response rates was found for the dental students. While $100 \%$ of the first-year (D1) and $99 \%$ of the second-year (D2) dental students participated, only $71 \%$ of the third-year (D3) and $24 \%$ of the fourth-year (D4) dental students did so. The overall response rate for the medical students was $27 \%$ : M1 students $25 \%$; M2 students $35 \%$; M3 students $34 \%$; and M4 students $13 \%$ of the approximately 175 students in each cohort.

The majority (94\%) of the dental hygiene students were female; approximately half of the dental and medical students ( $46 \%$ and $56 \%$, respectively) were female. The dental hygiene students were, on average, about two years younger than the dental and medical students because they attended the dental hygiene program as undergraduate students after 
having acquired one year of general undergraduate education. Overall, $73 \%$ of the students responded to the paper-and-pencil surveys and $27 \%$ to the webbased surveys.

While nearly all the responding students reported knowing that medical conditions, medications, and medical treatment/interventions can affect oral and maxillofacial health and that oral and maxillofacial health can affect systemic health, only $7 \%$ of the medical students agreed that they had sufficient knowledge in the oral, head, and neck region compared to $59 \%$ of the dental and $61 \%$ of the dental hygiene students (Table 1). When a sum score of the correct responses to these five questions was constructed, the medical students' average sum score was significantly lower than the dental hygiene and dental students' scores (on five-point scale: 4.06 vs. 4.61 vs. $4.55 ; \mathrm{p}<0.001)$.

The second subset of knowledge-related questions asked the students how much they knew about the scope of conditions treated by oral and maxillofacial surgeons and hospital dentists, these providers' roles in hospital and private practice settings, and their training. While the dental students had on average the most positive responses, the medical students had consistently the most negative responses to these questions (dental hygiene 3.77; dental 2.97; medical students $2.58 ; \mathrm{p}<0.001)$. A third subset of questions

Table 1. Intra- and interprofessional care (IPC)-related knowledge and skills: responses by type of student

\begin{tabular}{|c|c|c|c|c|}
\hline Question & $\begin{array}{l}\text { Dental Hygiene } \\
\qquad N=69\end{array}$ & $\begin{array}{l}\text { Dental } \\
N=316\end{array}$ & $\begin{array}{l}\text { Medical } \\
N=187\end{array}$ & p-value \\
\hline \multicolumn{5}{|l|}{ IPC knowledge-related questions (\%Yes) } \\
\hline Can medical conditions affect OM health? & $100 \%$ & $99 \%$ & $100 \%$ & 0.293 \\
\hline Can medications affect OM health? & $100 \%$ & $99 \%$ & $100 \%$ & 0.654 \\
\hline Can medical treatment/interventions affect OM health? & $100 \%$ & $99 \%$ & $100 \%$ & 0.442 \\
\hline Can OM health affect systemic health? & $100 \%$ & $99 \%$ & $100 \%$ & 0.491 \\
\hline Do you have sufficient knowledge about the oral, head, and neck region? & $61 \%$ & $59 \%$ & $7 \%$ & $<0.001$ \\
\hline Sum of correct responses ${ }^{a}$ (Mean) & 4.61 & 4.55 & 4.06 & $<0.001$ \\
\hline \multicolumn{5}{|l|}{ How much do you know about ${ }^{b}$} \\
\hline The scope of conditions treated by OM surgeons? & 2.71 & 3.64 & 2.34 & $<0.001$ \\
\hline The scope of conditions treated by hospital dentists? & 2.79 & 3.51 & 2.18 & $<0.001$ \\
\hline The role of OM surgeons in the hospital setting? & 2.85 & 3.70 & 2.45 & $<0.001$ \\
\hline The role of dentists in the hospital setting? & 3.00 & 3.59 & 2.12 & $<0.001$ \\
\hline The role of OM surgeons in a private practice setting? & 2.96 & 3.70 & 2.49 & $<0.001$ \\
\hline The role of dentists in a private practice setting? & 3.88 & 4.33 & 3.28 & $<0.001$ \\
\hline The training required to become an OM surgeon? & 2.72 & 4.04 & 3.21 & $<0.001$ \\
\hline The training required to become a hospital dentist? & 2.75 & 3.69 & 2.60 & $<0.001$ \\
\hline Knowledge index ${ }^{c}$ Cronbach's alpha $=0.934$ & 2.97 & 3.77 & 2.58 & $<0.001$ \\
\hline \multicolumn{5}{|l|}{ Skill-related questions: can you recognize/diagnose } \\
\hline Dental caries & $44 \%$ & $87 \%$ & $19 \%$ & $<0.001$ \\
\hline Periodontal disease & $58 \%$ & $79 \%$ & $12 \%$ & $<0.001$ \\
\hline Dental abscess & $39 \%$ & $82 \%$ & $27 \%$ & $<0.001$ \\
\hline Facial swelling & $59 \%$ & $79 \%$ & $34 \%$ & $<0.001$ \\
\hline Lymphadenopathy & $23 \%$ & $51 \%$ & $48 \%$ & $<0.001$ \\
\hline Maxillofacial trauma & $33 \%$ & $68 \%$ & $43 \%$ & $<0.001$ \\
\hline Cleft lip/palate & $58 \%$ & $83 \%$ & $59 \%$ & $<0.001$ \\
\hline Oral cancer & $25 \%$ & $59 \%$ & $20 \%$ & $<0.001$ \\
\hline Mucositis & $26 \%$ & $58 \%$ & $25 \%$ & $<0.001$ \\
\hline Oral fungal infection & $39 \%$ & $70 \%$ & $32 \%$ & $<0.001$ \\
\hline Oral viral infection & $13 \%$ & $51 \%$ & $15 \%$ & $<0.001$ \\
\hline Sum of skill-related Yes responses ${ }^{d}$ & 4.17 & 7.66 & 3.34 & $<0.001$ \\
\hline \multicolumn{5}{|l|}{ OM=oral and maxillofacial } \\
\hline \multicolumn{5}{|l|}{$\begin{array}{l}\text { The sum of correct responses was computed by adding one point for each Yes response. } \\
\text { bResponse options ranged from } 1=\text { nothing to } 5=\text { very much. } \\
\text { cThe knowledge index was computed by averaging responses to the eight items. } \\
\text { dThe skill index was computed by adding one point for each Yes response. }\end{array}$} \\
\hline
\end{tabular}


asked whether the students could recognize/diagnose 11 conditions. A sum score was computed by adding one point for each question answered affirmatively. Again, the medical students had the lowest sum score, followed by the dental hygiene students, while the dental students had the highest average sum scores of the three groups ( 3.34 vs. 4.17 vs. $7.66 ; p<0.001)$.

A total of 43 attitudinal items were included in the survey. These items had a Likert format with five-point answer scales from 1=disagree strongly to $5=$ agree strongly. The factor analysis showed that these items loaded on five factors. Average scores were computed for each of these five sets of responses to construct indices. The first set of five questions was related to how important the students believed it was to learn about oral and maxillofacial and medical issues in medical and dental school and in clinical settings (Table 2). All three student groups agreed/strongly agreed that this type of knowledge was important, with dental hygiene students having the most positive and medical students the least positive responses ( 4.77 vs. 4.61 vs. $4.49 ; \mathrm{p}=0.004)$. The second set of six items assessed how important it is that students know about relationships between oral and systemic health; how medical conditions, medications, and medical treatments affect oral and maxillofacial health; and whether students know the signs and symptoms of oral and maxillofacial disease and can perform/provide head and neck exams. While all the responding students had quite positive attitudes, the medical students were on average least positive overall and dental students the most positive (4.63 vs. 4.84 vs. $4.92 ; \mathrm{p}<0.001$ ).

The third set of nine items was concerned with the importance of having the skills to recognize and treat patients with various medical and oral health-

Table 2. Average attitudes of dental hygiene, dental, and medical students related to intra- and interprofessional education and knowledge/skills

\begin{tabular}{|c|c|c|c|c|}
\hline Attitude & Dental Hygiene & Dental & Medical & p-value \\
\hline \multicolumn{5}{|l|}{ Attitudes toward education: it is important that students learn about } \\
\hline OM health issues in medical school & 4.74 & 4.40 & 4.19 & $<0.001$ \\
\hline OM health issues in dental school & 4.88 & 4.74 & 4.79 & 0.227 \\
\hline OM health issues in clinical settings & 4.80 & 4.69 & 4.33 & $<0.001$ \\
\hline Medical issues in dental school & 4.72 & 4.57 & 4.35 & 0.001 \\
\hline Medical issues in clincial settings & 4.74 & 4.54 & 4.73 & 0.016 \\
\hline Attitudes toward education Cronbach's alpha $=0.891$ & 4.77 & 4.61 & 4.49 & 0.004 \\
\hline \multicolumn{5}{|l|}{ Attitudes toward knowledge: it is important that students } \\
\hline Know about the relationship between oral and systemic health & 4.84 & 4.70 & 4.53 & 0.003 \\
\hline Know how medical conditions affect oral health & 4.83 & 4.69 & 4.47 & $<0.001$ \\
\hline Know how medications affect oral health & 4.84 & 4.69 & 4.40 & $<0.001$ \\
\hline Know how medical treatments affect OM health & 4.79 & 4.75 & 4.41 & $<0.001$ \\
\hline Know the signs and symptoms of OM disease & 4.91 & 4.71 & 4.45 & $<0.001$ \\
\hline Can perform/provide head/neck exams & 4.84 & 4.70 & 4.61 & 0.066 \\
\hline Attitudes toward knowledge Cronbach's alpha $=0.749$ & 4.84 & 4.92 & 4.63 & $<0.001$ \\
\hline \multicolumn{5}{|c|}{$\begin{array}{l}\text { Attitudes about ability to treat: it is important that students can recognize and } \\
\text { treat patients with }\end{array}$} \\
\hline Facial trauma & 4.55 & 4.32 & 4.19 & 0.036 \\
\hline Dental abscess & 4.67 & 4.52 & 3.90 & $<0.001$ \\
\hline Oral cancer & 4.62 & 4.25 & 4.06 & 0.002 \\
\hline Cardiovascular risk factors & 4.52 & 4.25 & 4.51 & 0.003 \\
\hline Respiratory risk factors & 4.51 & 4.25 & 4.53 & 0.002 \\
\hline Diabetes & 4.55 & 4.33 & 4.52 & 0.027 \\
\hline Hematologic risk factors & 4.48 & 4.15 & 4.38 & 0.016 \\
\hline Developmental disabilities & 4.51 & 4.17 & 4.30 & 0.032 \\
\hline Acquired disabilities & 4.46 & 4.17 & 4.31 & 0.066 \\
\hline Attitudes about ability to treat Cronbach's alpha $=0.968$ & 4.54 & 4.27 & 4.30 & 0.063 \\
\hline
\end{tabular}

Note: Response options ranged from $1=$ disagree strongly to $5=$ agree strongly.

$\mathrm{OM}=$ oral and maxillofacial 
related concerns. The three student groups differed in eight of their nine responses. This difference was partially due to the fact that while medical students were least positive on questions about recognizing and treating facial trauma, dental abscesses, and oral cancer, dental students were least positive on questions about cardiovascular risk factors, respiratory risk factors, diabetes, hematologic risk factors, developmental disabilities, and acquired disabilities (Table 2).

While Table 2 provides an overview of the three sets of attitudinal items related to intra- and interprofessional knowledge and responsibilities, Table 3 shows the results concerning attitudes related to teamwork and communication with OMFS/hospital dentistry. A first set of five items was concerned with teamwork: specifically, how important it is to collaborate with medical doctors, hospital dentists, oral and maxillofacial surgeons, and other health care providers; and whether students consider oral health issues to be as important as systemic health issues. The average scores showed that the medical students were least positive, with the dental hygiene students being most positive ( 4.42 vs. 4.62 vs. 4.73 ; $\mathrm{p}=0.001)$. The final set of 18 attitudinal questions focused on how appropriate the students thought it was to consult with/refer patients with various conditions to OMFS and hospital dentistry. Average scores were computed for the responses concerning OMFS and hospital dentistry separately. While all the students had on average positive attitudes, the dental hygiene students' attitudes were most positive overall.

Three sets of items about the students' behavioral responses were analyzed. The first three items were yes/no questions related to whether the respondents routinely obtained health histories and

Table 3. Average attitudes of dental hygiene, dental, and medical students related to intra- and interprofessional care

\begin{tabular}{|c|c|c|c|c|c|}
\hline Attitude & & Dental Hygiene & Dental & Medical & p-value \\
\hline Attitudes about teamwork: it is important to & & & & & \\
\hline Collaborate with medical doctors & & 4.66 & 4.58 & 4.77 & 0.025 \\
\hline Collaborate with hospital dentists & & 4.71 & 4.57 & 4.58 & 0.404 \\
\hline Collaborate with oral and maxillofacial & & 4.71 & 4.63 & 4.52 & 0.187 \\
\hline Collaborate with other health care prov & & 4.74 & 4.57 & 4.73 & 0.032 \\
\hline See oral health issues to be as importan & nic health issues & 4.85 & 4.66 & 4.48 & 0.002 \\
\hline Overall: Cronbach's alpha $=0.818$ & & 4.73 & 4.62 & 4.42 & 0.001 \\
\hline $\begin{array}{l}\text { Attitudes about communication: it is appro } \\
\text { consult/refer to OMFS/hospital dentistry for }\end{array}$ & & & & & \\
\hline Tooth pain & OMFS & 3.98 & 3.18 & 4.07 & $<0.001$ \\
\hline & Hosp. dent. & 3.81 & 3.28 & 4.67 & $<0.001$ \\
\hline Dental trauma & OMFS & 4.46 & 4.15 & 4.69 & $<0.001$ \\
\hline & Hosp. dent. & 4.41 & 3.98 & 4.92 & 0.001 \\
\hline Implants & OMFS & 4.34 & 3.91 & 4.62 & $<0.001$ \\
\hline & Hosp. dent. & 3.86 & 3.43 & 4.36 & $<0.001$ \\
\hline Facial, oral, and pharyngeal abscesses & OMFS & 4.54 & 4.17 & 4.42 & $<0.001$ \\
\hline & Hosp. dent. & 4.51 & 4.06 & 4.14 & 0.002 \\
\hline Facial fracture/laceration & OMFS & 4.69 & 4.51 & 4.50 & $<0.135$ \\
\hline & Hosp. dent. & 4.54 & 4.07 & 3.69 & $<0.001$ \\
\hline Oral cancer & OMFS & 4.79 & 4.60 & 4.67 & 0.060 \\
\hline & Hosp. dent. & 4.67 & 4.34 & 3.95 & $<0.001$ \\
\hline Tracheostomy & OMFS & 4.46 & 4.53 & 3.96 & $<0.001$ \\
\hline & Hosp. dent. & - & - & - & - \\
\hline Cleft lip and palate & OMFS & 4.76 & 4.65 & 4.61 & 0.208 \\
\hline & Hosp. dent. & 4.59 & 4.22 & 3.72 & $<0.001$ \\
\hline Sleep apnea & OMFS & 3.72 & 3.98 & 3.80 & 0.082 \\
\hline & Hosp. dent. & 3.99 & 3.95 & 3.36 & $<0.001$ \\
\hline Overall Cronbach's alpha $=0.831$ & OMFS & 4.42 & 4.21 & 4.29 & 0.023 \\
\hline Overall Cronbach's alpha $=0.791$ & Hosp. dent. & 4.30 & 3.94 & 3.96 & 0.006 \\
\hline
\end{tabular}

Note: Response options ranged from $1=$ disagree strongly to $5=$ agree strongly.

OMFS=oral and maxillofacial surgery; Hosp. dent.=hospital dentistry 
performed oral and physical exams. While nearly all the dental hygiene and medical students reported that they obtained full health histories, only $61 \%$ of the dental students did so $(p<0.001)$ (Table 4). In contrast, only $18 \%$ of the medical students reported performing oral exams on their patients vs. $93 \%$ of dental hygiene and $90 \%$ of dental students $(p<0.001)$. The second set of seven questions asked the students whether they were comfortable obtaining a general health history, performing a head and neck exam, an oral exam, a full physical exam, recognizing abnormalities in the head and neck region and in the oral cavity, and recognizing a medical emergency. The average sum of Yes responses showed that the medical students were least comfortable and the dental hygiene students most comfortable with engaging in these behaviors ( 3.37 vs. 4.60 vs. $5.86 ; \mathrm{p}<0.001$ ). The final set of questions asked how comfortable the students were with consulting with oral and maxillofacial surgeons for extra-oral treatment and how comfortable they would be having an oral and maxillofacial surgeon operate on their own face outside the oral cavity. The results showed that while the dental students were most comfortable, the medical and dental hygiene students had on average neutral responses to these two questions ( 3.68 vs. 3.12 vs. $3.13 ; \mathrm{p}<0.001$ ).

We also compared the responses of first- and second-year vs. third- and fourth-year students
(Table 5). The fact that the dental hygiene students were in a three-year program and that the numbers of third- and fourth-year dental and medical students were rather low led to the decision to compare the responses of students in the preclinical cohorts with those of students in their third and fourth (clinical) years. Comparisons of the indices were conducted to analyze the question whether responses of the dental hygiene, dental, and medical students differed for these two student groups. The data showed that the earlier cohorts (first and second year) had less knowledge than the students in the later cohorts (third and fourth year). In addition, a significant interaction effect was found for the sum of correct knowledge-related responses. Medical students' average scores did not differ for the two groups, while both the dental hygiene and dental students' scores differed as expected, with the later cohorts having higher scores than students in the earlier cohorts. The average knowledge index score also differed as expected with the later cohorts having higher scores than the earlier cohorts. Concerning the sum of the skill-related Yes responses, the dental hygiene students' scores differed less than did the dental and medical students' scores.

The average attitude-related responses for all three student groups and all years were quite positive, with nearly all third- and fourth-year dental hygiene

\section{Table 4. Oral health-related behavior responses by type of student}

\begin{tabular}{|c|c|c|c|c|}
\hline Question & tal Hygiene & Dental & Medical & p-value \\
\hline \multicolumn{5}{|l|}{ Behavior-related questions: do you routinely (\% Yes) } \\
\hline Obtain full health histories from your patients? & $94 \%$ & $61 \%$ & $91 \%$ & $<0.001$ \\
\hline Perform oral exams on your patients? & $93 \%$ & $90 \%$ & $18 \%$ & $<0.001$ \\
\hline Perform a physical exam on your patients? & $27 \%$ & $26 \%$ & $53 \%$ & $<0.001$ \\
\hline Sum of oral health-related behaviors: mean & 2.07 & 2.03 & 1.20 & $<0.001$ \\
\hline \multicolumn{5}{|l|}{ Comfort-related questions: do you feel comfortable (\% Yes) } \\
\hline Obtaining a general health history? & $100 \%$ & $59 \%$ & $82 \%$ & $<0.001$ \\
\hline Performing a head \& neck exam? & $99 \%$ & $73 \%$ & $51 \%$ & $<0.001$ \\
\hline Performing an oral exam? & $97 \%$ & $79 \%$ & $23 \%$ & $<0.001$ \\
\hline Performing a full physical exam? & $29 \%$ & $22 \%$ & $69 \%$ & $<0.001$ \\
\hline Recognizing abnormalities in the head/neck region? & $88 \%$ & $73 \%$ & $34 \%$ & $<0.001$ \\
\hline Recognizing abnormalities in the oral cavity? & $91 \%$ & $83 \%$ & $19 \%$ & $<0.001$ \\
\hline Recognizing medical emergencies? & $83 \%$ & $63 \%$ & $60 \%$ & $<0.001$ \\
\hline Sum of behaviors student is comfortable with: mean & 5.86 & 4.60 & 3.37 & $<0.001$ \\
\hline \multicolumn{5}{|l|}{ How comfortable } \\
\hline Are you with consulting an oral and maxillofacial surgeon for extra-oral treatment? & 3.19 & 3.60 & 2.95 & $<0.001$ \\
\hline $\begin{array}{l}\text { Would you be if an oral and maxillofacial surgeon operated on your face outside } \\
\text { the oral cavity? }\end{array}$ & 3.07 & 3.73 & 3.20 & $<0.001$ \\
\hline Average level of comfort: mean Cronbach's alpha $=0.628$ & 3.13 & 3.68 & 3.12 & $<0.001$ \\
\hline
\end{tabular}


student scores being more different from their earlier cohorts' scores than the scores of the dental and medical students. Some of the third- and fourth-year medical student scores were even less positive than the scores of the first- and second-year medical students. The third- and fourth-year students' behavior-related indices such as sum of routine oral health-related behaviors, sum of behaviors with which students were comfortable, and average level of comfort were significantly higher than the first- and second-year students' scores (Table 5).

Table 6 provides an overview of how much the students' knowledge/skills scores correlated with their attitudinal and behavior indices. The more knowledge the students had, the better their skills were and the more positive their attitudes related to learning about intra- and interprofessional content, knowledge, responsibilities, teamwork, and communication. However, the sum of correct knowledge scores was not correlated with these attitudes.

\section{Discussion}

The Patient Protection and Affordable Care Act is changing the paradigm of health care delivery in the U.S. by stressing the importance of IPE and IPC..$^{45,46}$ By doing so, it aligns its policy with the recommendations of the World Health Organization, which advocates for IPC as a means to improve patient outcomes. ${ }^{47}$ In hospital settings where dental clearance is

Table 5. Comparisons of knowledge/skills, attitude, and behavior-related responses of first- and second-year versus third- and fourth-year dental hygiene, dental, and medical students

\begin{tabular}{|c|c|c|c|c|c|}
\hline Index/Attitudes & Year & $\begin{array}{l}\text { Dental } \\
\text { Hygiene }\end{array}$ & Dental & Medical & $\begin{array}{l}p \text {-value (Ye } \\
p \text {-value (Stu }\end{array}$ \\
\hline \multicolumn{6}{|l|}{ Knowledge and skills-related indices } \\
\hline Sum of correct knowledge-related responses & $\begin{array}{l}1 \& 2 \\
3 \& 4\end{array}$ & $\begin{array}{l}4.52 \\
4.88\end{array}$ & $\begin{array}{l}4.46 \\
4.76\end{array}$ & $\begin{array}{c}4.04 \\
4.10^{*}\end{array}$ & $\begin{array}{l}<0.001 \\
<0.001\end{array}$ \\
\hline Knowledge index & $\begin{array}{l}1 \& 2 \\
3 \& 4\end{array}$ & $\begin{array}{l}2.85 \\
3.35\end{array}$ & $\begin{array}{l}3.63 \\
4.09\end{array}$ & $\begin{array}{l}2.47 \\
2.75\end{array}$ & $\begin{array}{l}<0.001 \\
<0.001\end{array}$ \\
\hline Sum of skill-related "Yes" responses & $\begin{array}{l}1 \& 2 \\
3 \& 4\end{array}$ & $\begin{array}{l}4.00 \\
4.82\end{array}$ & $\begin{array}{l}6.76 \\
9.90\end{array}$ & $\begin{array}{c}1.91 \\
5.33^{*}\end{array}$ & $\begin{array}{l}<0.001 \\
<0.001\end{array}$ \\
\hline \multicolumn{6}{|c|}{ Attitudes related to intraprofessional and IPE and IPC knowledge/skills } \\
\hline Attitudes toward learning about IPC & $\begin{array}{l}1 \& 2 \\
3 \& 4\end{array}$ & $\begin{array}{l}4.73 \\
4.92\end{array}$ & $\begin{array}{l}4.57 \\
4.70\end{array}$ & $\begin{array}{l}4.50 \\
4.47\end{array}$ & $\begin{array}{l}0.164 \\
0.001\end{array}$ \\
\hline Attitudes toward IPC knowledge & $\begin{array}{l}1 \& 2 \\
3 \& 4\end{array}$ & $\begin{array}{l}4.81 \\
4.93\end{array}$ & $\begin{array}{l}4.97 \\
4.84\end{array}$ & $\begin{array}{l}4.63 \\
4.72 *\end{array}$ & $\begin{array}{c}0.482 \\
<0.001\end{array}$ \\
\hline Attitudes toward IPC skills & $\begin{array}{l}1 \& 2 \\
3 \& 4\end{array}$ & $\begin{array}{l}4.46 \\
4.78\end{array}$ & $\begin{array}{l}4.04 \\
4.69\end{array}$ & $\begin{array}{c}4.31 \\
4.29 * *\end{array}$ & $\begin{array}{l}0.001 \\
0.057\end{array}$ \\
\hline \multicolumn{6}{|l|}{ Attitudes related to intraprofessional care and IPC } \\
\hline Attitudes toward IPC & $\begin{array}{l}1 \& 2 \\
3 \& 4\end{array}$ & $\begin{array}{l}4.68 \\
4.88\end{array}$ & $\begin{array}{l}4.54 \\
4.76\end{array}$ & $\begin{array}{c}4.53 \\
4.24^{* *}\end{array}$ & $\begin{array}{c}0.591 \\
<0.001\end{array}$ \\
\hline Attitude toward consults/referrals with OMFS & $\begin{array}{l}1 \& 2 \\
3 \& 4\end{array}$ & $\begin{array}{l}4.38 \\
4.53\end{array}$ & $\begin{array}{l}4.11 \\
4.39\end{array}$ & $\begin{array}{c}4.43 \\
4.10^{* *}\end{array}$ & $\begin{array}{l}0.620 \\
0.071\end{array}$ \\
\hline Attitude toward consults/referrals with hospital dentistry & $\begin{array}{l}1 \& 2 \\
3 \& 4\end{array}$ & $\begin{array}{l}4.32 \\
4.22\end{array}$ & $\begin{array}{l}3.91 \\
3.93\end{array}$ & $\begin{array}{l}4.08 \\
3.78\end{array}$ & $\begin{array}{l}0.188 \\
0.024\end{array}$ \\
\hline \multicolumn{6}{|l|}{ Behavior-related indices } \\
\hline Sum of routine oral health-related behaviors & $\begin{array}{l}1 \& 2 \\
3 \& 4\end{array}$ & $\begin{array}{l}2.04 \\
2.18\end{array}$ & $\begin{array}{l}2.00 \\
2.11\end{array}$ & $\begin{array}{c}0.76 \\
1.80^{* *}\end{array}$ & $\begin{array}{l}<0.001 \\
<0.001\end{array}$ \\
\hline Sum of behaviors comfortable with recognizing/managing & $\begin{array}{l}1 \& 2 \\
3 \& 4\end{array}$ & $\begin{array}{l}5.85 \\
5.88\end{array}$ & $\begin{array}{l}4.03 \\
5.73\end{array}$ & $\begin{array}{c}2.40 \\
4.66^{* *}\end{array}$ & $\begin{array}{l}<0.001 \\
<0.001\end{array}$ \\
\hline Average level of comfort with IPC & $\begin{array}{l}1 \& 2 \\
3 \& 4\end{array}$ & $\begin{array}{l}3.07 \\
3.32\end{array}$ & $\begin{array}{l}3.57 \\
3.93\end{array}$ & $\begin{array}{l}3.08 \\
3.18\end{array}$ & $\begin{array}{c}0.029 \\
<0.001\end{array}$ \\
\hline Difficulty working with OMFS & $\begin{array}{l}1 \& 2 \\
3 \& 4\end{array}$ & $\begin{array}{l}2.84 \\
3.07\end{array}$ & $\begin{array}{l}2.68 \\
2.48\end{array}$ & $\begin{array}{l}2.44 \\
2.15\end{array}$ & $\begin{array}{c}0.472 \\
<0.001\end{array}$ \\
\hline Difficulty working with hospital dentistry & $\begin{array}{l}1 \& 2 \\
3 \& 4\end{array}$ & $\begin{array}{l}2.71 \\
2.85\end{array}$ & $\begin{array}{l}2.67 \\
2.43\end{array}$ & $\begin{array}{l}2.37 \\
2.38\end{array}$ & $\begin{array}{l}0.748 \\
0.030\end{array}$ \\
\hline
\end{tabular}

Note: Both types of $\mathrm{p}$-values are levels of significance for interaction effects Year $\mathrm{x}$ type of student.

IPE=interprofessional education; IPC=interprofessional care; OMFS=oral and maxillofacial surgery ${ }^{*} \mathrm{p}<0.05 ;{ }^{* *} \mathrm{p}<0.001$ 


\begin{tabular}{|c|c|c|c|}
\hline Category & $\begin{array}{l}\text { Sum of } \\
\text { Knowledge-Related } \\
\text { Responses }\end{array}$ & $\begin{array}{l}\text { Knowledge } \\
\text { Index }\end{array}$ & $\begin{array}{l}\text { Sum of } \\
\text { Skill-Related } \\
\text { Responses }\end{array}$ \\
\hline Knowledge index & $0.39 * * *$ & - & $0.54^{* * *}$ \\
\hline Sum of skill-related responses & $0.46^{* * *}$ & $0.54^{* * *}$ & - \\
\hline $\begin{array}{l}\text { Attitudes related to intraprofessional, IPE, and IPC knowledg } \\
\text { Attitudes toward learning about IPC } \\
\text { Attitudes toward IPC knowledge } \\
\text { Attitudes toward IPC skills }\end{array}$ & $\begin{array}{l}0.12^{* *} \\
0.17^{* * *} \\
0.05\end{array}$ & $\begin{array}{l}0.14^{* * *} \\
0.20^{* * *} \\
0.19^{* * *}\end{array}$ & $\begin{array}{l}-0.01 \\
0.22^{* * *} \\
0.01\end{array}$ \\
\hline $\begin{array}{l}\text { Attitudes related to intra- and interprofessional care } \\
\text { Attitudes toward IPC } \\
\text { Attitude toward consults/referrals with OMFS } \\
\text { Attitude toward consults/referrals with hospital dentistry }\end{array}$ & $\begin{array}{r}0.08 \\
0.01 \\
-0.04\end{array}$ & $\begin{array}{l}0.17^{* * *} \\
0.06 \\
-0.01\end{array}$ & $\begin{array}{l}-0.04 \\
-0.12^{* *} \\
-0.12 * *\end{array}$ \\
\hline $\begin{array}{l}\text { Behavior-related indices } \\
\text { Sum of routine oral health behaviors } \\
\text { Sum of routine oral health behaviors comfortable with } \\
\text { recognizing/managing } \\
\text { Average level of comfort with IPC } \\
\text { Difficulty working with OMFS } \\
\text { Difficulty working with hospital dentistry }\end{array}$ & $\begin{array}{l}0.39^{* * *} \\
0.36^{* * *} \\
0.17^{* * *} \\
-0.05 \\
-0.06\end{array}$ & $\begin{array}{l}0.32^{* * *} \\
0.32^{* * *} \\
0.59 * * * \\
-0.07 \\
-0.07\end{array}$ & $\begin{array}{l}0.42^{* * *} \\
0.40^{* * *} \\
0.28^{* * *} \\
-0.13^{*} \\
-0.11^{*}\end{array}$ \\
\hline $\begin{array}{l}\text { IPE=interprofessional education; OMFS }=\text { oral and maxillofacial } \\
{ }^{*} \mathrm{p}<0.05 ;{ }^{* *} \mathrm{p}<0.01 ;{ }^{* * *} \mathrm{p}<0.001\end{array}$ & gery & & \\
\hline
\end{tabular}

often a crucial prerequisite before surgeries and where poor oral health can endanger patients' lives, IPC is especially important. For example, for patients with congenital heart disease, the consequences of dental caries can be especially severe, as dental procedures and poor oral health put them at risk for infective endocarditis. ${ }^{48}$ The paradigm shift to IPC should therefore be a call to action for educators in all health professions programs. The main questions, however, are how successfully IPE can be implemented and whether this education can successfully impact students' knowledge/skills, attitudes, and behavior. One could argue that it might be easier for health care providers in dentistry and medicine to engage in IPC with organizational units that have a knowledge base rooted in both the dental and the medical sciences and are actually located in a medical center. OMFS departments and hospital dentistry units in hospital settings are two such units that qualify because they can be seen as having the role of addressing the IPC needs of patients. The objectives of this study therefore were to analyze the OMFS and hospital dentistry knowledge/ skills, attitudes, and professional behaviors of three groups of health professions students (dental hygiene, dental, and medical students).
The results paint a striking picture with a lack of OMFS and hospital dentistry-related knowledge/ skills juxtaposed to exceptionally positive attitudes and attitudes related to intra- and interprofessional knowledge, responsibilities, teamwork, and communication. Although all three student groups showed a clear awareness that medical conditions, medications, and medical treatments affect oral and maxillofacial health, the majority of the responding medical students admitted not having sufficient knowledge in the oral, head, and neck region. More importantly, the medical students reportedly knew, on average, very little about the scope of conditions treated by OMFS and hospital dentistry and the role of OMFS and hospital dentistry in private and even in hospital settings compared to both the dental and dental hygiene students, and they largely lacked the skills to diagnose oral health-related conditions such as maxillofacial trauma, lymphadenopathy, and oral viral infections. Not surprisingly, their actual interprofessional behavioral responses also reflected a lack of engagement in oral health-related care.

This lack of knowledge and behavioral engagement is surprising given the very positive average attitudes of all three groups of students concerning 
having students learn about OMFS health issues in medical and dental school and clinical settings and the importance of IPC. Students in all three programs also had highly positive attitudes concerning consults/referrals to OMFS and hospital dentistry for a number of conditions. Given this scenario of a lack of knowledge and behavioral engagement on one hand and highly positive attitudes on the other hand, the question arises whether an educational deficit concerning OMFS content might explain this situation.

This question can be partially answered by comparing the students' responses in the first and second years vs. the third and fourth years of their programs. The fact that no consistent knowledge increase occurred among the medical students could be interpreted as evidence of a lack of effective educational efforts for these students. Even more concerning should be the finding that more advanced cohorts of medical students had less positive interprofessional attitudes than the earlier cohorts. This result raises the question of how motivated future medical providers are to engage in IPC if their attitudes become less positive over the course of their medical education, given the empirical evidence that attitudes are related to behavior. ${ }^{49}$ Future research should therefore focus on a careful curricular analysis for all three programs to determine the extent to which the three programs engage their students in intra- and interprofessional education. In addition, it is crucial to gain a better understanding of why increased intra- and interprofessional knowledge was not related to more positive attitudes toward consults/referral with OMFS and hospital dentistry and especially why higher skills were related to more negative attitudes related to communication, specifically consults/referrals with OMFS and hospital dentistry. While students themselves do not actually initiate consults/referrals so their faculty advisors are responsible for these professional behaviors, the students nevertheless are being educated about these types of professional behaviors and should respond more affirmatively in this area. These findings thus raise the question of whether increased skills could imply that providers develop the perception of having a diminished need to engage in intra- and interprofessional care.

Given the calls for IPC, health professions schools must institute a collaborative learning and practice approach for students to become familiar with the IPC model and obtain the knowledge and skills to function as members of interprofessional teams upon graduation. ${ }^{50}$ Curriculum modifications and integration among the various health professions schools are necessary to achieve these goals. ${ }^{7,19}$ Assessing the current climate within and between programs for an optimal understanding of where to focus efforts in collaborative learning and skills training focused on integrated patient care is important for optimally preparing students to function in the collaborative health care delivery model of the future. ${ }^{7,19,33,51}$

This study had several limitations. First, the response rates for the fourth-year dental and medical students were low. Organizational considerations need to be considered in this context. The third- and fourth-year dental students attend a dental school that requires them to spend considerable amounts of time in rotations (ten weeks) and community-based dental education (12 weeks). During this time, these students did not attend the classes in which we handed out surveys, so we did not expect to have a high response rate from the D3s and D4s. When students were in class and responded to our surveys, they did not represent a biased sample of students, but they merely were the students currently not on rotations or in community-based clinics. Similarly, the third- and fourth-year medical students were engaged in clinical rotations and did not have required attendance for classes because all lectures were recorded and available as podcasts. Collecting data in classroom settings was therefore impossible for the medical students. The medical students and third- and fourthyear dental students on rotations and in communitybased settings were therefore invited to participate with an email, informing them about the study and asking them to use a Web link in the email to respond to the anonymous survey. Hardigan et al. found that email requests in general did not result in as high a response rate as more personal recruitment efforts. ${ }^{52}$

Second, the dental hygiene program at our institution is only three years, so, for comparative measures, the groups of dental hygiene, dental, and medical students were grouped into only two cohort categories. The first- and second-year dental and medical students and the second-year dental hygiene students (called second year because they had an initial year of college education elsewhere) were considered to be in their preclinical years and grouped together. The third- and fourth-year students in all three programs were in their clinical years and were therefore also grouped together. However, future research should analyze the change over the four years of the medical and dental curricula to gain a better understanding of which specific programmatic 
aspects leads to changes in students' knowledge/ skills, attitudes, and behavior.

Third, it must also be recognized that all respondents were from one institution with only beginning efforts to engage in intra- and interprofessional activities. While it seems reasonable to generalize these findings to other institutions with beginning efforts, it is not possible to generalize these findings to institutions with more developed and sophisticated IPE efforts. Future research should focus on including programs at institutions at different stages of efforts.

Lastly, the intra- and interprofessional questions focused on OMFS and hospital dentistry, which have roots in both medicine and dentistry. Further research should analyze how IPC with medical care providers and OMFS and hospital dentistry providers can be optimized. In addition, it would be beneficial to extend the considerations of IPC efforts to other groups of oral health care providers and to clearly delineate their roles and responsibilities in the complex framework of providing optimal care for all patients, whether as in- or out-patients in the hospital setting.

\section{Conclusion}

As expected, this study found that the responding medical students had less knowledge about OMFS and hospital dentistry and a lower level of diagnostic skills related to oral conditions than the dental hygiene and dental students. In addition, they were less likely to engage in related professional behavior compared to students in the other two groups. However, the students in all three groups and at all years in the curriculum had on average rather positive intra- and interprofessional attitudes. When the responses of first- and second-year vs. third- and fourth-year students were compared, the average knowledge/skillsrelated responses of the three groups of students and the responses of the earlier vs. later cohorts differed. The later medical student cohorts had significantly higher average skill-related responses than the earlier medical cohorts. However, the later medical student cohorts had no more positive attitudes toward IPE and interprofessional knowledge and even poorer attitudes toward interprofessional teamwork and communication (specifically, consults/referrals with OMFS and hospital dentistry) than the earlier medical student cohorts. While interprofessional knowledge/ skills and behavior were related as expected, knowledge was not related to attitudes toward consults/ referrals with OMFS and hospital dentistry, and interprofessional skills were even negatively related with consults/referrals to these units. These findings can be considered indicators of the baseline status quo when no major IPE efforts have been implemented. Future research should carefully monitor changes in interprofessional knowledge/skills, attitudes, and behavior when such efforts are implemented.

\section{Acknowledgments}

We want to thank the students who took time to respond to these surveys. We also want to thank Hyunjung Shin for his efforts to prepare the data for analysis and Paul Yoon for his support of the organizational efforts involved in this study.

\section{REFERENCES}

1. Oral health in America: a report of the surgeon general. Rockville, MD: U.S. Department of Health and Human Services, National Institute of Dental and Craniofacial Research, National Institutes of Health, 2000.

2. American Academy of Pediatrics Section on Pediatric Dentistry and Oral Health, Crall J, Krol D, et al. Preventive oral health intervention for pediatricians. Pediatrics 2008;122(6):1387-94.

3. Olson R, Bialocerkowski A. Interprofessional education in allied health: a systematic review. Med Educ 2014;48: 236-46.

4. Rafter ME, Pesun IJ, Herren M, et al. A preliminary survey of interprofessional education. J Dent Educ 2006;70(4):417-26.

5. Graham E, Negron R, Domoto P, Milgrom P. Children's oral health in the medical curriculum: a collaborative intervention at a university-affiliated hospital. J Dent Educ 2003;67(3):338-47.

6. Kim S, Mouradian WE, Slayton RL. What every doctor should know about oral health. Med Educ 2006;40: 459-89.

7. Gambhir RS. Primary care in dentistry: an untapped potential. J Fam Med Prim Care 2015;4(1):13-8.

8. Munro N, Felton A, McIntosh C. Is multidisciplinary learning effective among those caring for people with diabetes? Diabet Med 2002;19:799-803.

9. Bell KP, Phillips C, Paquette DW, et al. Dental hygienists' knowledge and opinions of oral-systemic connections: implications for education. J Dent Educ 2011;76(6): 682-94.

10. Griffin SO, Barker LK, Griffin PM, et al. Oral health needs among adults in the United States with chronic diseases. J Am Dent Assoc 2009;140(10):1266-74.

11. Gurenlian JR. Interprofessional education and practice. J Dent Educ 2015;79(5):548-50.

12. Paquette DW, Bell KP, Phillips C, et al. Dentists' knowledge and opinions of oral-systemic disease relationships: relevance to patient care and education. J Dent Educ 2015;79(6):626-35.

13. Griffin SO, Jones JA, Brunson D, et al. Burden of oral disease among older adults and implications for public health priorities. Am J Public Health 2012;102:411-8. 
14. Hendricson W, Cohen P. Oral health care in the $21 \mathrm{st}$ century: implications for dental and medical education. Acad Med 2001;76(12):1181-206.

15. Migliorati C, Madrid C. The interface between oral and systemic health: the need for more collaboration. Clin Microbiol Infect 2007;13(4):11-6.

16. Berwick DM, Nolan TW, Whittington J. The triple aim: care, health, and cost, the remaining barriers to integrated care are not technical; they are political. Health Aff 2008;27(3):759-69.

17. Abu-Rish E, Kim S, Choe L, et al. Current trends in interprofessional education of health sciences students: a literature review. J Interprof Care 2012;26(6):444-51.

18. Berkowitz O, Kaufman LB, Russell M. Introduction of an interprofessional oral health curriculum. J Physician Assist Educ 2015;26(1):43-6.

19. Formicola AJ, Andrieu SC, Buchanan JA, et al. Interprofessional education in U.S. and Canadian dental schools: an ADEA team study group report. J Dent Educ 2012;76(9):1250-68.

20. Commission on Dental Accreditation. Accreditation standards for dental hygiene education programs. 2013. At: www.ada.org/ /media/CODA/Files/dh.ashx. Accessed 27 Sept. 2015.

21. Commission on Dental Accreditation. Accreditation standards for dental education programs. 2013. At: www.ada. org/ /media/CODA/Files/predoc.ashx. Accessed 27 Sept. 2015.

22. Association of American Medical Colleges. Oral health in medicine competencies for the undergraduate medical education curriculum. 2011. At: www.mededportal.org/ download/258096/data/ohicompetencies.pdf. Accessed 27 Sept. 2015.

23. Furgeson D, Kinney JS, Gwozdek AE, et al. Interprofessional education in U.S. dental hygiene programs: a national survey. J Dent Educ 2015;79(11):1286-94.

24. Ritchie C, Dann L, Ford PJ. Shared learning for oral health therapy and dental students: enhanced understanding of roles and responsibilities through interprofessional education. Eur J Dent Educ 2012;17:e56-63.

25. Brame JL, Mitchell SH, Wilder RS, et al. Dental and allied dental students' attitudes towards and perceptions of intraprofessional education. J Dent Educ 2014;79(6):61625.

26. Morison S, Marley J, Stevenson M, Milner S. Preparing for the dental team: investigating the views of the dental and dental care professional students. Eur J Dent Educ 2008;12:23-8.

27. Mouradian WE, Reeves A, Kim S, et al. A new oral health elective for medical students at the University of Washington. Teach Learn Med 2006;18(4):336-42.

28. Darlow B, Coleman K, McKinlay E, et al. The positive impact of interprofessional education: a controlled trial to evaluate a program for health professional students. BMC Med Educ 2015;15(98):1-9.

29. Stolberg RL, Bilich LA. Dental team experience (DTE): a five-year experience. J Dent Hyg 2012;86(3):223-30.

30. McCloskey L, Condon R, Shanahan CW, et al. Public health, medicine, and dentistry as partners in community health: a pioneering initiative in interprofessional, practice-based education. J Public Health Manag Pract 2011;17(4):298-307.
31. Pardue KT. Not left to chance: introducing an undergraduate interprofessional education curriculum. J Interprof Care 2013;27(1):98-100.

32. Van Winkle LJ, Cornell S, Fjortoft N, et al. Critical thinking and reflection exercises in a biochemistry course to improve prospective health professions students' attitudes toward physician-pharmacist collaboration. Am J Pharm Educ 2013;77(8):article 169.

33. Gilbert JHV. Interprofessional education for collaborative, patient-centered practice. Can J Nurs Leadership (Tor Ont) 2005; 18(2):32-6,8.

34. Gill Y, Scully C. Attitudes and awareness of final-year predoctoral dental and medical students to medical problems in dentistry. J Dent Educ 2006;70(9):991-5.

35. Rabiei S, Mohebbi SZ, Patja K, et al. Physicians' knowledge of and adherence to improving oral health. BMC Public Health 2012;12(855):1-9.

36. Rodehorst TK, Wilhelm SL, Jensen L. Use of interdisciplinary simulation to understand perceptions of team members' roles. J Prof Nurs 2005;21(3):159-66.

37. Zhang S, Lo ECM, Chu CH. Attitude and awareness of medical and dental students towards collaboration between medical and dental practice in Hong Kong. BMC Oral Health 2015;15(53).

38. Solomon P, Risdon C. A process oriented approach to promoting collaborative practice: incorporating complexity methods. Med Teach 2014;36(9):821-4.

39. Jackson JT, Quinonez RB, Kerns AK, et al. Implementing a prenatal oral health program through interprofessional collaboration. J Dent Educ 2015;79(3):241-8.

40. Leisnert L, Karlsson M, Franklin I, et al. Improving teamwork between students from two professional programs in dental education. Eur J Dent Educ 2011;16:17-26.

41. Sohn W, Ismail AI, Tellez M. Efficacy of educational intervention targeting primary care providers' practice behaviors: an overview of published systematic reviews. J Public Health Dent 2004;64(3):164-72.

42. MacDonald MB, Bally JM, Ferguson LM, et al. Knowledge of the professional role of others: a key interprofessional competency. Nurse Educ Pract 2009;10:238-42.

43. Interprofessional Education Collaborative. Core competencies for interprofessional collaborative practice: report of an expert panel, 2011. At: www.aacn.nche.edu/ education-resources/IPECReport.pdf. Accessed 23 Aug. 2015.

44. Czarnecki GA, Kloostra SJ, Boynton JR, Inglehart MR. Nursing and dental students' and pediatric dentistry residents' responses to experiences with interprofessional education. J Dent Educ 2014;78(9):1301-12.

45. The Patient Protection and Affordable Care Act: detailed summary. At: www.dpc.senate.gov/healthreformbill/ healthbill04.pdf. Accessed 9 Nov. 2015.

46. Zorek J, Raehl C. Interprofessional accreditation standards in the USA: a comparative analysis. J Interprof Care 2013;27(2):123-30.

47. World Health Organization, Department of Human Resources for Health. Framework for action on interprofessional education and collaborative practice. Geneva: World Health Organization, 2010.

48. Wilson W, Taubert KA, Gewitz M, et al. Prevention of infective endocarditis: guidelines from the American Heart Association Rheumatic Fever, Endocarditis, and Kawasaki 
Disease Committee, Council on Cardiovascular Disease in the Young, Council on Clinical Cardiology, Council on Cardiovascular Surgery and Anesthesia, and Quality of Care and Outcomes Research Interdisciplinary Working Group. Circulation 2007;116(15):1736-54.

49. Fishbein M, Ajzen I. Belief, attitude, intention, and behavior: an introduction to theory and research. Reading, MA: Addison-Wesley, 1975.

50. Lockhart PB, Brennan MT, Thronhill M, et al. Poor oral hygiene as a risk factor for infective endocarditis related bacteremia. J Am Dent Assoc 2009;140(10):1238-44.
51. Schmitt M, Blue A, Aschenbrener CA, et al. Core competencies for interprofessional collaborative practice: reforming health care by transforming health professionals' education. Acad Med 2011;86(11):1351.

52. Hardigan PC, Succar CT, Fleisher JM. An analysis of response rate and economic costs between mail and webbased surveys among practicing dentists: a randomized trial. J Community Health 2012;37(2):383-94. 